\title{
KARAKTERISTIK FRUIT LEATHER JAMBU BIJI MERAH (Psidium guajava $L$ ) DENGAN JENIS BAHAN PENGISI
}

\author{
Dede Zainal Arief \\ Leni Herliani Afrianti \\ Soemarni \\ Program Studi Teknologi Pangan, Fakultas Teknik, Universitas Pasundan, Jl. Dr.Setiabudi No 93, Bandung, \\ 40153, Indonesia \\ E-mail : ariefalbuchari@gmail.com
}

\begin{abstract}
Abstrak
Tujuan penelitian yang telah dilakukan untuk menentukan jenis bahan pengisi yang mampu memperbaiki karakteristik fruit leather jambu biji merah. Manfaat dari penelitian diantaranya sebagai upaya penganeka ragaman produk olahan buah jambu biji merah yang sering berlimpah saat musim berbuah. Penelitian dilakukan dengan rancangan percobaan Acak Kelompok (RAK) dengan 2 faktor, dan diulang sebanyak 3 kali. Produk fruit leather jambu biji merah yang terpilih adalah produk dengan perlakuan $\mathrm{j}_{1} \mathrm{t}_{1}$ (jenis pengisi dekstrin dan suhu pengeringan $50^{\circ} \mathrm{C}$ ). Jenis bahan pengisi dan suhu pengeringan hanya berpengaruh terhadap kadar air. Dari hasil pengamatan tidak terjadi interaksi antara jenis pengisi dan suhu pengeringan terhadap karakteristik fruit leather jambu biji merah.
\end{abstract}

\begin{abstract}
The purpose of this research is to determine the type of filler material that is able to improve the characteristics of fruit leather red guava. The benefits of such research as a processed product diversification of red guava fruit is often abundant fruiting season. The study was conducted with a randomized experimental design (RAK) with 2 factors, and repeated 3 times. Product guava fruit leather red elect is a product with j1t1 treatment (type of filler dextrin and drying temperature of $50^{\circ} \mathrm{C}$ ). Type of filler material and drying temperature affects only the water content. From the observation no interaction between the types of fillers and drying temperature on the characteristics of red guava fruit leather.
\end{abstract}

Keyword: filler, Fruit leather, Characteristics.

\section{Pendahuluan}

Jambu biji (Psidium Guajava L), merupakan salah satu jenis buah tropis yang banyak dibudidayakan di berbagai tempat di Indonesia. Pada tahun 2005 Produksi jambu biji di Indonesia sebesar 178.509 ton, tahun 2006 sebesar 196.180 ton, tahun 2007 sebesar 179.474 ton, tahun 2008 sebesar 207.025 ton, dan tahun 2009 mencapai 220.202 ton (BPS, 2005-2009).

Produksi jambu biji tersebut diserap oleh pasar dalam negeri dan luar negeri. Data BPS 2004, menunjukkan Negara-negara tujuan ekspor jambu biji segar meliputi, Hongkong (> 66 ton), Singapura (7,6 ton), Malaysia (4,1 ton), Saudi Arabia (2,6 ton), Belanda (2,7 ton), dan Bulgaria (1,5 ton).

Produksi jambu biji di Jawa Barat terus meningkat dari tahun ke tahun selama 5 tahun terakhir. Menurut data BPS Jawa Barat tahun 2005, produksi jambu biji (49.552 ton) lebih tinggi dibandingkan jeruk (2.380 ton), sirsak (23.143 ton), markisa (163 ton), dan belimbing (11.774 ton). Produksi jambu biji untuk daerah Jawa Barat pada tahun 2006 sebesar 47.735 ton. Produksi jambu biji terus meningkat dalam dua tahun dan mencapai puncak pada tahun 2008 sebesar 65.131 ton. Tahun 2009, Jawa Barat mencapai peringkat pertama di Indonesia (70.799 ton).

Saat ini dikenal beberapa varietas jambu biji, yaitu Vietnamese, Kahuakula, Allahabad Safeda, Fan Ratief, Beamount, dan Hongkong Pink (Yusof, 2003). Di Indonesia dikenal empat jenis jambu biji, yaitu jambu biji Merah, jambu Sukun, jambu Susu dan jambu Bangkok (Satuhu, 2003).

Buah jambu biji banyak mengandung vitamin $\mathrm{C}$, asam amino (tritofan, lisin), kalsium, fosfor, besi, belerng, vitamin A dan $\mathrm{B}_{1}$. Jambu biji biasanya dimakan dalam keadaan segar, baik masih hijau maupun sudah matang (Dalimartha, 2000).

Buah jambu biji mempunyai rasa khas dan keasamannya $(\mathrm{pH})$ berkisar antara 4,0-5,2 
(Chopda dan Barret, tanpa tahun). Bagian terpenting dari jambu biji adalah buahnya. Buah yang sudah matang selain enak dikonsumsi, juga mengandung gizi yang cukup tinggi. Selain pensuplai gizi, buah jambu biji bermanfaat meningkatkan daya tahan tubuh terhadap infeksi (Rukmana, 1996).

Buah jambu biji berkhasiat untuk menyembuhkan beberapa penyakit, diantaranya kencing manis, kadar kolesterol tinggi, demam berdarah, dan diare. (Dalimartha, 2000). Buah jambu biji mengandung senyawa fitokimia seperti likopen, karoten, polifenol, dan flavonoid. Satu diantaranya adalah karoten yang mengandung provitamin A yang di dalam tubuh diubah menjadi vitamin $\mathrm{A}$. Bersama dengan vitamin $\mathrm{C}$ dan vitamin E, vitamin A berfungsi sebagai antioksidan yang dapat menangkal radikal bebas penyebab kerusakan sel dan proses penuaan dini, menurunkan resiko berbagai penyakit degeneratif (jantung, diabetes, katarak, hipertensi), dan kanker (Afriyanti, 2010).

Kadar vitamin $\mathrm{C}$ dalam jambu biji paling banyak $(116,0 \mathrm{mg} / 100 \mathrm{~g})$ billa dibandingkan dengan buah papaya $(83,5 \mathrm{mg} / 100 \mathrm{~g})$, jeruk $(30,0$ $\mathrm{mg} / 100 \mathrm{~g})$, serikaya $(28,3 \mathrm{mg} / 100 \mathrm{~g})$, dan nanas $(22$ $\mathrm{mg} / 100 \mathrm{~g}$ ) (Daftar komposisi pangan dan gizi Indonesia, 2006). Selain mengandung vitamin C jambu biji juga mengandung pektin yang tinggi, sehingga dapat digunakan sebagai bahan untuk membuat gel/jeli.

Salah satu masalah yang dihadapi dalam menangani hasil panen buah jambu biji oleh petani maupun pedagang adalah cepatnya penurunan mutu setelah buah dipetik. Buah jambu biji yang sudah dipetik atau dijual dalam keadaan segar hanya mampu bertahan selama satu minggu dalam penyimpanan suhu ruang. Buah jambu biji yang tidak langsung dikonsumsi atau diberi perlakuan khusus akan membusuk. Kebanyakan jambu biji yang dihasilkan hanya dikonsumsi dalam keadaan segar. Hal tersebut tidak menguntungkan, karena buah segar mudah mengalami kerusakan (Satuhu \& Syaifullah., 2003).

Buah jambu biji dapat bertahan sampai 15 hari jika disimpan dalam gudang dengan menggunakan kantong plastik pada suhu $23-25{ }^{\circ} \mathrm{C}$ ditambah 7 hari setelah dikeluarkan dari kantong, sehingga dapat meningkatkan daya simpan 4,4 kali dibandingkan tanpa perlakuan tersebut. Buah jambu biji dapat disimpan sampai 5 minggu pada suhu $8-10{ }^{0} \mathrm{C}$ dan kelembaban 85-95 \% (Soedarya, 2009).

Menurut Rukmana (1996), Jambu biji merupakan salah satu jenis buah yang belum mendapat perhatian khusus di Indonesia. Sampai sejauh ini jambu biji jarang dimanfaatkan atau mendapat perhatian khusus. Oleh karena itu perlu dikembangkan olahan alternatif buah jambu biji agar memiliki umur simpan yang lebih lama, jangkauan pemasaran yang lebih luas, dan untuk mengamankan hasil panen yang berlimpah. Dilihat dari potensi hasil panen jambu biji sangat besar. Buah jambu biji yang ditanam di kebun atau di pekarangan menghasilkan 360 buah/pohon/tahun. Jambu biji unggul menghasilkan 3.600 buah/pohon/tahun.

Hasil pengolahan buah jambu biji yang sudah dilakukan diantaranya : sari buah, selai, jeli, dodol, jus, manisan, permen, dan asinaan (Soedarya, 2009). Pengolahan dengan proses pengeringan pada jambu biji sangat mungkin dikembangkan untuk penganekaragaman produk. Dengan adanya pengolahan jambu biji maka jambu biji bisa dinikmati pada setiap saat walaupun bukan musim jambu biji. Salah satu produk olahan jambu biji dengan proses pengeringan adalah fruit leather yang memiliki umur simpan lebih lama yaitu 8-12 bulan (Enie $d k k .$, 1993).

Berdasarkan fakta di lapangan, harga jambu biji merah lebih murah (Rp.4.000,- s/d Rp.6.000,per $\mathrm{kg}$ ) dibandingkan jambu biji Bangkok (Rp.8.000,-s/d 12.000,- per kg), karena ketersediaan jambu biji merah melimpah di pasaran daripada jambu biji berwarna putih. Kunjungan ke beberapa perkebunaan jambu biji (Padalarang, Subang dan Banjaran), para petani umumnya hanya menanam jambu biji merah karena permintaan pasar.

Produk fruit leather jambu biji merah nampaknya di pasaran dalam negeri masih sedikit, padahal produk ini sangat menguntungkan. Keuntungan produk fruit leather diantaranya penyimpanan dan transfortasi menjadi lebih mudah, kadar air rendah sehingga tidak mudah terkotori dan terjangkiti bibit penyakit serta praktis karena siap dikonsumsi (Kumalaningsih $d k k$., 2005).

Permasalahan pada pembuatan fruit leather jambu biji merah adalah pencoklatan produk. Salah satu upaya pengendalian pencoklatan adalah dengan cara pengaturan suhu pengeringan. Suhu pengeringan yang terlalu tinggi menyebabkan hilangnya senyawa-senyawa volatil (aroma), kerusakan vitamin $\mathrm{C}$ dan reaksi pencoklatan dari sukrosa yang ada di dalam bahan pangan. Suhu pengeringan yang rendah menyebabkan proses pengeringan kurang efisien dan juga mendorong kerusakan selama proses (Suryanto, 2000).

Kandungan air pada buah jambu biji merah cukup tinggi yaitu sekitar 70-78 \% sehingga agak sulit dalam pembuatan fruit leather, terutama saat proses pengeringan. Oleh karena itu dalam prosesnya memerlukan suatu bahan tambahan sebagai pengikat yang dapat memperbaiki campuran bubur jambu sebagai bahan dasar agar zat-zat tersebut dapat bercampur. Bahan pengikat yang digunakan dapat berfungsi juga sebagai bahan pengisi (Suci, 1993). Jenis bahan pengisi 
yang digunakan untuk membuat fruit leather umumya berasal dari kelompok karbohidrat seperti pektin, gum arab, dekstrin, maizena, tapioka, karagenan, asam alginat, dan agar-agar (Winarno, 2002).

Selain jenis pengisi dan suhu pengeringan, masalah utama dalam pembuatan fruit leather jambu biji merah adalah keplastisan, yaitu tekstur yang lunak, mudah digulung dan tidak retak/pecah. Penambahan sukrosa saja akan menghasilkan tekstur fruit leather yang lebih keras karena akan terjadi kristalisasi gula, sehingga harus diimbangi dengan glukosa cair. Glukosa digunakan dengan tujuan untuk menambah rasa manis dan melunakakan tekstur (Andari, 2001).

Perbandingan sukrosa dengan glukosa dan waktu pengeringan yang tepat akan menghasilkan fruit leather jambu biji merah yang bermutu, oleh karena itu perlu diteliti perbandingan antara sukrosa dengan glukosa dan waktu pengeringan yang tepat yang tepat.

Atas dasar uraian tersebut di atas selanjuntnya penelitian dilakukan dengan rumusan masalah sebagai berikut :

1. Apakah jenis pengisi dan suhu pengeringan yang bervariasi berpengaruh terhadap karakteristik fruit leather jambu biji merah?

2. Apakah terjadi interaksi antara jenis pengisi dan suhu pengeringan terhadap karakteristik fruit leather jambu biji merah?

Maksud penelitian adalah menentukan jenis bahan pengisi dan suhu pengeringan yang tepat dalam pembuatan fruit leather jambu biji merah.

Penelitian dilakukan dengan tujuan untuk menghasilkan fruit leather jambu biji merah dengan kulitas fisik, kimia dan organoleptik yang baik.

Diharapkan hasil penelitian memiliki kegunaan dalam memberikan pengetahuan cara pembuatan fruit leather jambu biji dengan berbagai bahan pengisi yang bisa digunakan dan menambah diversifikasi produk olahan jambu biji merah. Selain itu diharapkan hasil penelitian dapat diterapkan guna meningkatkan nilai ekonomis jambu biji, meningkatkan taraf hidup petani, dan menjadi makanan kudapan yang sehat bagi masyarakat karena mengandung vitamin $\mathrm{C}$ dan zat gizi lainnya.

\section{Metode Penelitian}

Penelitian menggunakan Rancangan Acak Kelompok (RAK) yang disusun secara faktorial dengan 2 faktor (Gasperz, 1995). Masing-masing faktor terdiri dari 3 level dengan 3 kali ulangan. Sebagai faktor pertama jenis pengisi $\left(j_{1}=\right.$ Dekstrin, $\mathrm{j}_{2}=$ Gum Arab, dan $\mathrm{j}_{3}=$ Tapioka) mengacu kepada penelitian Fernilopa (2008), dengan konsentrasi masing-masing 1\%. Faktor kedua adalah suhu pengeringan $\left(t_{1}=50^{\circ} \mathrm{C}, \quad t_{2}=60^{\circ} \mathrm{C}\right.$, dan $t_{3}=70^{\circ} \mathrm{C}$ mengacu pada penelitian Henneman, 1993).

Respon penelitian meliputi kadar air dan $\mathrm{pH}$ (Sudarmadji, $d k k, 1997$; AOAC, 1995), serta uji organoleptik (Soekarto, 1995) fruit leather.

Uji organoleptik dilakukan dengan menggunakan uji hedonik (Soekarto, 1995) berdasarkan tingkat kesukaan atau penerimaan panelis, meliputi warna, rasa, aroma dan tekstur. Penentuan perlakuan terbaik berdasarkan metode uji skoring. Uji hedonik dilakukan oleh panelis dengan kriteria penilaian tertentu. Selanjutnya data hasil organoleptik dianalisis secara statistik.

Untuk membuktikan adanya pengaruh perlakuan dan interaksinya terhadap semua respon variabel yang diamati, maka dilakukan analisa variansi (ANAVA)

Kesimpulan, hipotesa $\left(\mathrm{H}_{\mathrm{o}}\right)$ diterima jika ada pengaruh nyata antara nilai rata-rata dari masingmasing perlakuan. Hipotesa $\left(\mathrm{H}_{\mathrm{o}}\right)$ ditolak jika ada pengaruh tidak nyata antara nilai rata-rata dari masing-masing perlakuan ( $\mathrm{F}$ hitung $>\mathrm{F}$ tabel) yang dicobakan, maka perlu dilakukan pengujian lanjut berupa uji jarak berganda Duncan (Gasperz, 1995).

\section{Hasil danPembahasan}

Percobaan didahului dengan analisis buah jambu biji merah segar.

Tabel 1. Analisis kimia Jambu Biji Merah varietas getas

\begin{tabular}{|c|l|c|}
\hline No. & Parameter & Kadar \\
\hline 1. & Kadar Air $(\%)$ & 74,75 \\
\hline 2. & $\mathrm{pH}$ & 4,10 \\
\hline 3. & Kadar Gula Total $(\%)$ & 10,30 \\
\hline 4. & Kadar Vitamin C (mg/100g) & 108,04 \\
\hline
\end{tabular}

Tabel 1. memperlihatkan kadar air buah jambu biji merah getas sebesar $74,75 \%$. Menurut Herdianto (1992), kadar air buah jambu biji merah sebesar 72,3\%, dan menurut Fress (1999) 84,87\%. Perbedaan dapat terjadi pada varietas jambu yang sama tergantung tingkat kematangan dan kesegaran buah yang diuji. Dengan kadar air sebesar 74,75\% berarti buah jambu biji merah getas memiliki kandungan air yang cukup tinggi, sehingga perlu ditambahkan bahan pengisi untuk dibuat fruit leather. Tujuan penambahan bahan pengisi adalah untuk meningkatkan total padatan produk yang dihasilkan dan menurunkan kadar air (Putri, 2007). Dengan demikian bahan pengisi yang ditmbahkan harus memiliki sifat menarik air (hidrofilik). Sifat hidrofilik tersebut, dapat mempengaruhi struktur pangan dan sifat-sifat yang berkaitan dengan kelarutan atau kekentalan (Tranggono, 1998).

Selain kadar air faktor $\mathrm{pH}$, dan kadar gula total juga menjadi syarat pembuatan fruit leather. Hasil pengukuran $\mathrm{pH}$ jambu biji merah adalah 
4,10, berarti jambu biji merah bersifat asam lemah. Untuk itu perlu ditambahkan asam sitrat sebesar $0,2 \%$ (Fress, 1999) untuk menurunkan $\mathrm{pH}$ agar tercapai $\mathrm{pH}$ fruit leather sebesar 3,0-3,4 (Suci, 1993). Suasana asam diperlukan dalam fruit leather untuk mempertahankan kandungan vitamin $\mathrm{C}$ agar tidak mudah rusak dan memberikan rasa yang segar. $\mathrm{pH}$ dapat mencegah oksidasi asam askorbat (Muchtadi, 2008).

Kadar gula total dalam jambu biji merah getas sebesar 10,30\%, yang terdiri dari glukosa, sukrosa dan fruktosa. Untuk menghasilkan fruit leather yang memenuhi standar perlu penambahan gula ke dalam adonan sebesar 10-15 \% (Satuhu, 1994). Gula yang ditambahkan biasanya dalam bentuk sukrosa dan glukosa. Penambahan sukrosa dengan glukosa dapat menghasilkan tekstur yang liat dan plastis (Andari, 2001).

Kadar vitamin $\mathrm{C}$ dalam jambu merah sebesar $108,04 \mathrm{mg} / 100 \mathrm{~g}$. Berdasarkan sumber pustaka kadar vitamin $\mathrm{C}$ dalam buah jambu biji putih 104 $\mathrm{mg} / 100 \mathrm{~g}$ dan dalam buah jambu biji merah sebesar $126 \mathrm{mg} / 100 \mathrm{~g}$ (Parimin, 2005). Kadar vitamin C dalam buah jambu merah termasuk tinggi, tetapi mudah rusak, terutama akibat oksidasi oleh panas (Winarno, 2002).

Analisis buah jambu biji merah yang dilakukan menjadi dasar pembahasan berbagai respon yang diamati dalam pembuatan fruit leather jambu biji merah pada percobaan tahap-1 dan 2 .

\section{Penentuan jenis bahan pengisi dan suhu pengeringan}

Jenis bahan pengisi dan suhu pengeringan berperan besar terhadap hasil olahan bahan pangan. Untuk menentukan jenis bahan pengisi dan suhu pengeringan yang tepat dapat dilakukan dengan cara uji fisik, kimia, dan organoleptik. Analisis kimia yang dilakukan terhadap karakteristik fruit leather jambu biji merah pada penelitian tahap-1 adalah kadar air dan $\mathrm{pH}$.

\section{Kadar air}

Berdasarkan hasil analisis statistik, tidak terjadi interaksi antara jenis bahan pengisi dan suhu pengeringan terhadap kadar air fruit leather jambu biji merah. Secara mandiri jenis bahan pengisi dan suhu pengeringan berpengaruh nyata terhadap kadar air fruit leather jambu biji merah.

Hasil uji lanjut Duncan 5\% (Tabel 2), menunjukkan bahwa kadar air fruit leather jambu biji merah dengan penambahan jenis bahan pengisi gum arab $(13,67 \%)$ dan tapioka $(12,91 \%)$ berbeda nyata dengan penambahan jenis bahan pengisi dekstrin $(10,10 \%)$. Penambahan jenis bahan pengisi dekstrin menghasilkan fruit leather jambu biji merah dengan kadar air paling rendah dan penambahan jenis bahan pengisi gum arab menghasilkan fruit leather jambu biji merah dengan kadar air paling tinggi.
Tabel 2. Pengaruh jenis bahan pengisi terhadap kadar air.

\begin{tabular}{|c|c|}
\hline Jenis bahan Pengisi $(\mathbf{J})$ & Kadar Air $(\%)$ \\
\hline Dekstrin $\left(\mathrm{j}_{1}\right)$ & 10,10 \\
& $\mathrm{a}$ \\
\hline Gum arab $\left(\mathrm{j}_{2}\right)$ & 13,67 \\
& $\mathrm{~b}$ \\
\hline Tapioka $\left(\mathrm{j}_{3}\right)$ & 12,91 \\
& $\mathrm{~b}$ \\
\hline
\end{tabular}

Keterangan : Nilai rata-rata yang diikuti huruf berbeda menunjukkan perbedaan nyata pada taraf $5 \%$.

Hal tersebut terjadi karena dekstrin mudah larut dalam air, tetapi cepat terdispersi, dan tidak kental, sehingga berfungsi sebagai filler. Dengan demikian air yang diikat oleh dekstrin cepat teruapkan, sehingga kadar air menjadi rendah. Dekstrin berguna sebagai agen pengikat yang dapat membantu pengeringan (Kumalaningsih., $d k k$, 2000). Sedangkan gum Arab, dengan konsentrasi 1-5\% membentuk larutan dengan kekentalan yang tinggi karena sifat emulsifier dan stabilizer, yang berfungsi sebagai pembentuk gel. Dengan demikian, jumlah air yang diuapkan lebih sedikit, sehingga kandungan airnya lebih banyak. Syarat kandungan air dalam fruit leather sebesar 10-15\% (Enie $d k k ., 1993$ ).

Hasil uji lanjut Duncan 5\% (tabel 3), menunjukkan bahwa kadar air fruit leather jambu biji merah dengan suhu pengeringan $50^{\circ} \mathrm{C}$ $(13,23 \%)$ dan $60^{\circ} \mathrm{C} \quad(12,35 \%)$ secara statistik berbeda nyata dengan suhu pengeringan $70^{\circ} \mathrm{C}$ $(11,10 \%)$.Suhu pengeringan $50^{\circ} \mathrm{C}$ menghasilkan fruit leather jambu biji merah dengan kadar air tertinggi.

Tabel 3. Pengaruh suhu pengeringan terhadap kadar air.

\begin{tabular}{|c|c|}
\hline Suhu pengeringan $(\mathbf{T})$ & Kadar air $(\%)$ \\
\hline $50{ }^{0} \mathrm{C}\left(\mathrm{t}_{1}\right)$ & 13,23 \\
& $\mathrm{~b}$ \\
\hline $60{ }^{0} \mathrm{C}\left(\mathrm{t}_{2}\right)$ & 12,35 \\
& $\mathrm{~b}$ \\
\hline $70{ }^{0} \mathrm{C}\left(\mathrm{t}_{3}\right)$ & 11,10 \\
& $\mathrm{a}$ \\
\hline
\end{tabular}

Keterangan : Nilai rata-rata yang diikuti huruf berbeda menunjukkan perbedaan nyata pada taraf $5 \%$.

Kadar air tertinggi adalah pada perlakuan dengan jenis pengisi gum arab pada suhu $50^{\circ} \mathrm{C}\left(\mathrm{j}_{2} \mathrm{t}_{1}\right)$ sebesar $14,46 \%$, sedangkan pada perlakuan dengan jenis pengisi dekstrin pada suhu $70^{\circ} \mathrm{C}\left(\mathrm{j}_{1} \mathrm{t}_{3}\right)$ diperoleh kadar air terendah yaitu $8,09 \%$. 
Kadar air fruit leather jambu biji merah mengalami perubahan setelah penambahan jenis pengisi dan pengeringan. Semakin tinggi suhu pengeringan, kadar air dalam bahan akan semakin rendah. Hal tersebut disebabkan kecepatan aliran udara makin cepat sehingga proses pengeringan berlangsung lebih cepat. Kadar air yng terkandung dalam bahan akan teruapkan lebih banyak dengan suhu yang tinggi (Ishak, 1993).

\section{Nilai pH}

Berdasarkan hasil analisis statistik, tidak terjadi interaksi antara jenis bahan pengisi dan suhu pengeringan terhadap nilai $\mathrm{pH}$ fruit leather jambu biji merah. Secara mandiri jenis bahan pengisi dan suhu pengeringan tidak berpengaruh nyata terhadap nilai $\mathrm{pH}$ fruit leather jambu biji merah.

Nilai $\mathrm{pH}$ fruit leather jambu biji merah mengalami perubahan setelah penambahan jenis bahan pengisi dan pengeringan. Dari Tabel 4, ternyata penambahan jenis bahan pengisi dapat menurunkan nilai $\mathrm{pH}$ dari 4,1 menjadi 3,99 untuk dekstrin, menjadi 3,81 untuk gum Arab, dan 3,87 untuk tapioka. Dari data juga terlihat pada suhu pengeringan yang rendah $\mathrm{pH}$ yang terukur juga rendah atau suasana asam campuran semakin bertambah.

Dengan demikian berarti semakin tinggi suhu pengeringan maka suasana asam semakin berkurang, karena semakin banyak asam yang menguap. Asam mudah rusak oleh panas dengan suhu yang tinggi.

Tabel 4. Pengaruh jenis bahan pengisi dan suhu pengeringan terhadap $\mathrm{pH}(\mathrm{pH}$ jambu segar $=4.10$ ).

\begin{tabular}{|c|c|c|c|}
\hline $\begin{array}{c}\text { Jenis bahan } \\
\text { pengisi }\end{array}$ & $\begin{array}{c}\mathrm{pH} \\
\text { campuran }\end{array}$ & $\begin{array}{c}\text { Suhu } \\
\text { pengeringan }\left({ }^{0} \mathrm{C}\right)\end{array}$ & $\begin{array}{c}\mathrm{pH} \text { setelah } \\
\text { pengeringan }\end{array}$ \\
\hline Dekstrin & 3,99 & 50 & 3,63 \\
& & 60 & 3,63 \\
& & 70 & 3,68 \\
\hline Gum & 3,81 & 50 & 3,60 \\
Arab & & 60 & 3,68 \\
& & 70 & 3,69 \\
\hline Tapioka & 3,87 & 50 & 3,59 \\
& & 60 & 3,65 \\
& & 70 & 3,68 \\
\hline
\end{tabular}

Untuk menghasilkan fruit leather jambu biji merah dipilih jenis pengisi dekstrin, suhu pengeringan $50{ }^{0} \mathrm{C}$, dan penambahan asam sitrat dinaikkan dari $0,2 \%$ menjadi $0,3 \%$ agar tercapai $\mathrm{pH}$ fruit leather sebesar 3,0-3,4 (Suci,1993).

Uji organoleptik yang dilakukan pada penelitian tahap-1 terhadap karakteristik fruit leather jambu biji merah pada adalah warna, aroma, rasa, dan tekstur.

Berdasarkan analisis statistik, tidak terjadi interaksi antara jenis bahan pengisi dan suhu pengeringan terhadap warna, aroma, rasa, dan tekstur fruit leather jambu biji merah. Demikian juga secara mandiri jenis bahan pengisi dan suhu pengeringan tidak berpengaruh nyata terhadap warna, aroma, rasa, dan tekstur fruit leather jambu biji merah.

\section{Warna fruit leather jambu biji merah}

Tidak adanya perbedaaan yang nyata pada warna fruit leather jambu biji merah menunjukkan terjadinya pencampuran yang merata pada saat pengolahan. Keseragaman warna menunjukkan kualitas pencampuran bahan pada saat pengolahan (Winarno, 2002).

Jambu biji merah banyak mengandung karotenoid, diantaranya likopen, karoten, antosianin, tannin, metil benzoat, $p$-feniletil asetat, metil sinamat, sinamil asetat, dan $\beta$ ionon (Yusof, 2000). Faktor-faktor yang mempengaruhi perubahan warna pada pigmen karotenoid diantaranya adalah cahaya, panas, dan asam. Senyawa-senyawa karotenoid umumnya bersifat volatil dan peka terhadap kenaikan suhu. Suhu $60^{\circ} \mathrm{C}$ menyebabkan hilangnya senyawa-senyawa volatil tersebut (Yusof, 2003). Berarti dengan bahan baku yang bersifat asam yaitu $\mathrm{pH}$ jambu biji merah sebesar 4,10 dan penggunaan suhu pengeringan yang tidak terlalu tinggi (kurang dari $80^{\circ} \mathrm{C}$ ), menyebabkan pigmen pada fruit leather jambu biji merah relatif stabil (Deman, 1997).

Nilai kesukaan panelis tertinggi terhadap warna fruit leather jambu biji merah adalah perlakuan $\mathrm{j}_{1} \mathrm{t}_{1}$ (jenis pengisi dekstrin pada suhu pengeringan $50^{\circ} \mathrm{C}$ ) dan $\mathrm{j}_{3} \mathrm{t}_{1}$ (jenis pengisi tapioka pada suhu pengeringan $50^{\circ} \mathrm{C}$ ), dengan skor 5 . Kedua perlakuan yang paling disukai adalah pada suhu $50{ }^{\circ} \mathrm{C}$, baik pengisi dekstrin maupun tapioka. Pada suhu pengeringan sebesar $50^{\circ} \mathrm{C}$ tidak terjadi reaksi pencoklatan. Menurut Winarno (2003), reaksi pencoklatan dapat terjadi secara enzimatik dan non enzimatik. Reaksi non enzimatis berupa karamelisasi dan reaksi mailard. Karamelisasi hanya terjadi apabila suhu sangat tinggi, sedangkan reaksi mailard akan terjadi bila terkandung protein tinggi. Diduga reaksi pencoklatan yang terjadi adalah reaksi pencoklatan enzimatik. Proses pencoklatan enzimatik memerlukan enzim fenol oksidase dan oksigen yang harus berhubungan dengan substrat senyawa fenolik. Buah-buahan banyak mengandung senyawa fenolik. Buah jambu biji mengandung senyawa polifenol. Terjadinya reaksi pencoklatan diperkirakan melibatkan perubahan bentuk kuinol menjadi kuinon yang dipacu dengan kenaikan suhu.

Penambahan dekstrin menyebabkan proses pengeringan lebih cepat tanpa terjadinya reaksi pencoklatan. Namun semakin tinggi konsentrasi dekstrin, warna produk jambu biji merah semakin merah muda atau putih. Hal tersebut 
mempengaruhi derajat penerimaan panelis (Suryanto, 2000).

\section{Aroma fruit leather jambu biji merah}

Tidak adanya perbedaaan yang nyata pada aroma fruit leather jambu biji merah, karena jenis bahan pengisi yang digunakan berasal dari satu kelompok yang sama yaitu karbohidrat.

Menurut Tranggono (1998), suatu senyawa karbohidrat mampu menyerap senyawa volatil dari lingkungan sekitarnya dan menahan senyawa tersebut dengan kuat selama pengeringan.

Nilai kesukaan panelis tertinggi untuk aroma fruit leather jambu biji merah adalah perlakuan $\mathrm{j}_{1} \mathrm{t}_{1}$ (jenis pengisi dekstrin dan suhu pengeringan $50^{\circ} \mathrm{C}$ ), $\mathrm{j}_{2} \mathrm{t}_{1}$ (jenis pengisi gum arab dan suhu pengeringan $50^{\circ} \mathrm{C}$ ), dan perlakuan $\mathrm{j}_{3} \mathrm{t}_{1}$ (jenis pengisi tapioka dan suhu pengeringan $50^{\circ} \mathrm{C}$ ) dengan skor 5 .

Ketiga perlakuan bahan pengisi (dekstrin, gum Arab dan tapioka) yang paling disukai adalah pada suhu $50^{\circ} \mathrm{C}$. Hal tersebut disebabkan pada suhu $60-70^{\circ} \mathrm{C}$ senyawa-senyawa volatil lebih cepat menguap dibanding pada suhu. Suhu pengeringan yang tinggi menyebabkan hilangnya senyawasenyawa volatil pada bahan yang dikeringkan (Darniadi, 2006)

Senyawa-senyawa volatil dalam buah jambu biji merah peka terhadap kenaikan suhu (Yusof, 2003). Senyawa-senyawa utama yang bersifat volatil yang terdapat pada buah jambu biji merah adalah ester-ester alkohol alifatik dan asam-asam lemak berantai pendek(yang terbentuk bila terjadi fermentasi pada buah yang masak), alkohol dengan rantai bercabang (valin dan leusin), Aldehid dan keton yang diduga berasal dari alkohol melalui oksidasi (Matto, dkk., 1996).

\section{Rasa fruit leather jambu biji merah}

Tidak adanya perbedaaan yang nyata pada rasa fruit leather jambu biji merah disebabkan jumlah bahan-bahan yang ditambahkan relatif sama dan buah jambu biji yang digunakan memiliki tingkat kematangan serta besar buah yang relatif sama, sehingga kandungannya tidak terlalu berbeda.

Ada 22 senyawa yang berperan dalam aroma dan rasa yaitu : metil benzoat, hexanol, $p$-fenil etil asetat, metil sinamat, sinamil asetat, dan $\beta$ ionon. Terdapat 122 senyawa volatil yang telah diidentifikasi berupa aldehid 13, keton 17, alkohol 31 , asam-asam 10, ester 28, dan hidrokarbon 10 (Yusof, 2003).

Nilai kesukaan panelis tertinggi untuk rasa fruit leather jambu biji merah adalah pada perlakuan $\mathrm{j}_{1} \mathrm{t}_{1}$ (jenis pengisi dekstrin dan suhu pengeringan $50^{\circ} \mathrm{C}$ ), $\mathrm{j}_{2} \mathrm{t}_{1}$ (jenis pengisi gum arab dan suhu pengeringan $50^{\circ} \mathrm{C}$ ), dan perlakuan $\mathrm{j}_{3} \mathrm{t}_{1}$ (jenis pengisi tapioka dan suhu pengeringan $50^{\circ} \mathrm{C}$ ), dengan skor 5. Ketiga perlakuan bahan pengisi (dekstrin, gum Arab dan tapioka) yang paling disukai adalah pada suhu $50^{\circ} \mathrm{C}$. Hal tersebut disebabkan pada suhu $60-70^{\circ} \mathrm{C}$ senyawa-senyawa volatil akan lebih mudah hilang yang disertai berkurangnya kandungan air, sehingga mempengaruhi rasa fruit leather jambu biji merah.

\section{Tekstur fruit leather jambu biji merah}

Nilai kesukaan panelis tertinggi untuk tekstur fruit leather jambu biji merah adalah perlakuan $\mathrm{j}_{1} \mathrm{t}_{1}$ (jenis pengisi dekstrin dan suhu pengeringan $50^{\circ} \mathrm{C}$ ), $\mathrm{j}_{2} \mathrm{t}_{1}$ (jenis pengisi gum arab dan suhu pengeringan $50^{\circ} \mathrm{C}$ ), dan perlakuan $\mathrm{j}_{3} \mathrm{t}_{1}$ (jenis pengisi tapioka dan suhu pengeringan $50^{\circ} \mathrm{C}$ ), dengan skor 5. Ketiga perlakuan bahan pengisi (dekstrin, gum Arab dan tapioka) yang paling disukai adalah pada suhu $50^{\circ} \mathrm{C}$. Hal tersebut disebabkan penambahan glukosa cair yang sama sebanyak $1 \%$ dan pengeringan pada suhu $60-70^{\circ} \mathrm{C}$ menyebabkan kandungan air semakin berkurang, sehingga fruit leather jambu biji merah semakin kering dan teksturnya makin tidak plastis.

Tekstur yang diharapkan dari produk fruit leather jambu biji merah adalah tekstur yang besifat plastis. Penggunaaan bahan pengisi dengan tambahan glukosa cair dapat membantu menghasilkan produk yang bertekstur plastis (Puspitasari, 1999).

Penambahan sukrosa tanpa disertai penambahan glukosa cair akan menghasilkan tekstur fruit leather yang mudah retak, karena sukrosa mudah menyerap air, yang disebabkan memiliki gugus -OH yang lebih banyak dibandingkan dengan glukosa. Fruktosa memiliki bentuk yang sama dengan gukosa yaitu D, tetapi mempunyai arah rotasi yang berbeda. Fruktosa memutar ke kiri, sedangkan glukosa memutar ke kanan. Dengan arah putaran yang berbeda, akan terjadi tarik menarik sehingga terjadilah tekstur yang plastis, jika glukosa jumlahnya lebih banyak dari fruktosa (Fessenden, 1992). Jadi penambahan sukrosa disertai glukosa cair akan meningkatkan jumlah glukosa daripada fruktosa.

\section{Penentuan Perlakuan Terbaik}

Perlakuan terbaik percobaan tahap-1 dipilih berdasarkan uji skoring untuk semua respon. Perlakuan terbaik berdasarkan hasil uji scoring adalah $\mathrm{j}_{1} \mathrm{t}_{1}$ dan $\mathrm{j}_{3} \mathrm{t}_{1}$. Jenis bahan pengisi terpilih adalah dekstrin $\left(\mathrm{j}_{1}\right)$ dan tapioka $\left(\mathrm{j}_{3}\right)$, sedangkan suhu pengeringan terpilih adalah suhu $50^{\circ} \mathrm{C}\left(\mathrm{t}_{1}\right)$. Total skor perlakuan $\mathrm{j}_{1} \mathrm{t}_{1}$ dan $\mathrm{j}_{3} \mathrm{t}_{1}$ adalah 20 (Tabel 5).

Tabel 5.Hasil uji skoring penelitian tahap-1

\begin{tabular}{|c|c|c|c|c|c|}
\hline Perlakuan & Warna & Aroma & Rasa & Tekstur & Total \\
\hline $\mathrm{j}_{1} \mathrm{t}_{1}$ & $\mathbf{5}$ & $\mathbf{5}$ & $\mathbf{5}$ & $\mathbf{5}$ & $\mathbf{2 0}$ \\
\hline $\mathrm{j}_{1} \mathrm{t}_{2}$ & 2 & 3 & 4 & 4 & 13 \\
\hline $\mathrm{j}_{1} \mathrm{t}_{3}$ & 3 & 5 & 3 & 3 & 14 \\
\hline $\mathrm{j}_{2} \mathrm{t}_{1}$ & 4 & 4 & 5 & 5 & 18 \\
\hline $\mathrm{j}_{2} \mathrm{t}_{2}$ & 4 & 1 & 2 & 2 & 9 \\
\hline $\mathrm{j}_{2} \mathrm{t}_{3}$ & 2 & 5 & 4 & 4 & 15 \\
\hline $\mathrm{J}_{3} \mathrm{t}_{1}$ & $\mathbf{5}$ & $\mathbf{5}$ & $\mathbf{5}$ & $\mathbf{5}$ & $\mathbf{2 0}$ \\
\hline
\end{tabular}




\begin{tabular}{|l|l|l|l|l|l|}
\hline $\mathbf{J}_{3} \mathrm{t}_{2}$ & 3 & 2 & 3 & 3 & 11 \\
\hline $\mathrm{J}_{3} \mathrm{t}_{3}$ & 3 & 3 & 3 & 3 & 12 \\
\hline
\end{tabular}

Perlakuan $\mathrm{j}_{1} \mathrm{t}_{1}$ menjadi dasar penelitian tahap-2, karena kadar air dengan tambahan jenis bahan pengisi dekstrin lebih kecil $(11,45 \%)$ dibandingkan tapioka $(13,79 \%)$. Semakin rendah kadar air bahan maka akan semakin lama umur simpannya (Winarno, 2002)

Berdasarkan hasil penelitian dapat disimpulkan ecara mandiri jenis pengisi (dekstrin, gum arab, tapioka) dan variasi suhu pengeringan tidak berpengaruh terhadap nilai $\mathrm{pH}$ dan semua respon organoleptik yang diamati, tetapi berpengaruh terhadap kadar air fruit leather jambu biji merah, tidak terjadi interaksi antara jenis pengisi dan suhu pengeringan terhadap semua respon yang diamati, enggunaan jenis pengisi dekstrin dan suhu pengeringan $50^{\circ} \mathrm{C}\left(\mathrm{j}_{1} \mathrm{t}_{1}\right)$ meng hasilkan karakteristik warna, aroma, rasa dan tekstur fruit leather jambu biji merah yang disukai oleh panelis.

\section{Daftar Pustaka}

1. Afrianti, H.L., 2010. 33 Macam Buah-buahan Untuk Kesehatan. Bandung : Penerbit Alfabeta.

2. Andari, D. 2001. Pengaruh Konsentrasi bahan Pengisi (CMC) Dan Perbandingan Sukrosa dengan Glukosa Terhadap Karakteristik Fruit Leather Salak Manonjaya (Sallaca Edulis Reinw). Skripsi. Bandung : FT Unpas

3. AOAC. 1995. Officiall Methods of The Association of Official Analytical Chemistry. Washington D.C.

4. BPS. 2009. Produksi Buah-buahan di Indonesia (1995-2009). Melalui $<$ bps.go.id/tab_sub/view.php?tabel=1dndaftar =1\&id_subyek> (24/11/2010).

5. BPS Provinsi Jabar. 2009. Produksi Buahbuahan menurut Jenis di Jawa Barat (19952009).

6. BPS 2004. Data Ekspor. Jakarta.

7. Buckle, K.A., Edwards, G.H., Fleet and Wootton. 1997. Ilmu Pangan, Terjemahan Purnomo. H, dan Adiono. Jakarta : UI Press.

8. Daliarmartha, S. 2000. Atlas Tumbuhna Obat Indonesia, Jakarta : Trubus Agriwidya.

9. Darniadi, S. 2006. Kajian Konsentrasi Dekstrin Dan Tween 80 Yang bervariasi Terhadap Bubuk Sari Buah Jambu Biji Merah (Psidium Guajava L) Yang Dibuat Dengan Metode Foam-Mat Drying, Tesis Master. Bandung : Unpas.

10. Deman, J.M. 1997. Kimia Makanan. Edisi Kedua. Bandung: Penerbit ITB.
11. Departemen Kesehatan. 1996. Daftar Komposisi Zat Gizi Pangan Indonesia. Jakarta : Puslitbang Gizi.

12. Enie, A.B. Nami, Lestari dan Syukri, A., 1993. Pengembangan Buah-buahan Tropis Untuk Pembuatan Olahan Eksotis (Fruit Leather. Laporan Hasil Penelitian dan Pengembangan, BBPPIHP, Departemen Perindustrian.

13. Fessenden, J. R. dan Fessenden, S. J. 1990. Kimia Organik jilid 2. Jakarta : Edisi Ketiga, Penerbit Erlangga.

14. Fress, D. 1999. Pengaruh Suhu Pengeringan dan Konsentasi Gula Terhadap Karakteristik Vegetable Leathers Jambu Biji (Psidium Guajava L.). TA. Bandung : FT Unpas.

15. Gaspersz, V. 1995. Teknik Analisis Dalam Penelitian Percobaan. Edisi Pertama. Bandung : Penerbit Tarsito.

16. Henneman, M.S. 1993. Drying Fruit Leather, http//www.pleasathillgrain.com, Accesed : Desember 2010.

17. Herliana, E. 1999. Pengaruh Bahan Pengisi dan Konsentrasi Sukrosa Terhadap Karakteristik Mutu Fruit Leather Mangga, TA. Bandung : FT Unpas.

18. International Centre for Underutilised Crops, UK.(2004). Processing of Fruit Lether. http://www.icuk-iwmi.org (Akses 08/04/2010).

19. Kumalaningsih, Suprayogi, Beni Y.M.W. 2005. Membuat Makanan Siap Saji. Surabaya : Trubus Agrisarana.

20. Lumingkewas, M, Kumolontang, Karinda Clartje, Muis J., dan Limbalo A. 1994. Penelitian Pengolahan Buah-buahan Menjadi Produk Olahan Eksotis (Fruit Leather), BPPI, Departemen Perindustrian.

21. Matto, $d k k$., 1996. Perubahan-perubahan Kimiawi Selama Pematangan dan Penuaaan dalam Pantastico E.B. (ed). Yogyakarta Fisiologi Pasca Panen, Penangann dan Pemanfaatan Buah-buahan dan Sayursayuran Tropika dan Subtropika .hlm.160189.Terjemhan kamariyani . : Gadjah Mada Universty Press.,

22. Muchtadi, R. T, dan Sugiyono. 1992. Petunjuk Laboratorium Ilmu Pengetahuan Bahan Pangan. Bogor : Depdikbud Dikti Pusat Antar Universitas Pangan, Penerbit IPB.

23. Parimin, S. P., 2005. Budi Daya Dan Ragam Pemanfaatanny Jambu Biji. Jakarta :Penerbit PT Penebar Swadya.

24. Putri, A. J. 2007. Pengaruh Jenis dan Konsentrasi Bahan Pengisi Terhadap Karakteristik Fruit Leather Belimbing Wuluh (Averhoa bilimbi L), TA. Bandung : FT Unpas. 
25. Rukmana., R. 1996. Jambu Biji, Yogyakarta: Kanisius.

26. Satuhu, S dan Syaifullah. 2000. Kajian sifat fisik Dan Kimia Beberapa Varietas Jambu Biji. Jurnal HortikulturaVolume 1(4) : 53-56. Jakarta : Balai Penelitian Holtikultura.

27. Satuhu, S., 2003. Penanganan Dan Pengolahan Buah. Jakarta : Penebar Swadaya.

28. Soekarto, S. T. 1995. Penilaian Organoletik. Bogor: Pusbangtepa IPB.

29. Soedarya, A.P. 2009. Agribisnis Guava (Jambu Batu). Bandung: Pustaka Grafika.

30. Suci, 1993. Mengawetkan Buah Menjadi Leather. Jakarta : Trubus No. 285 Th XXIV.

31. Sudarmadji, S., B. Haryono, dan Suhardi. 1997. Analisa Bahan Makanan dan Pertanian. Yogyakarta : Liberty

32. Suryanto, R. 2000. Pembuatan Bubuk Sari Buah Sirsak (Annona Muricata L) dari Bahan Baku Pasta dengan Metode Foam-Mat Drying. Tesis Master. Malang: Unibraw.

33. Tranggono. 1998. Bahan Tambahan makanan. Yogyakarta : Edisi pertama. UGM

34. Winarno, F.G. 2002. Kimia Pangan Dan Gizi. Jakarta : Edisi Kedelapan. PT. Gramedia Pustaka Utama,

35. Wueller, L., 2008. Drying Fruit Leather. http ://extens.missouri.edu. (Akses : 17/12/2008)

36. Yusof, S. 2003. Guava in Caballero, B, Luiz, C. T, Paul, M. F, Encyclopedia of Food Sciences and Nutrition, page, 2985-2991. $2^{\text {nd }}$. NewYork: Academic Press. 